\title{
The Spectral and Statistical Analysis of Gait Dynamics in ALS Disease
}

\author{
O. AKGUN, A. AKAN and O. YILMAZ
}

\begin{abstract}
Amyotrophic lateral sclerosis (ALS) disease, also known as motor neuron disease, is a disease resulting from loss of motor nerve cells in the spinal cord and brain stem region at central nervous system. Researchers can't find the reason of ALS for certain, however there are a wide variety of risk factors in respect of this disease. This disease has more than one risk factor. Researchers believe that it is resulted from a virus which leads to abnormality in immune system, spoils the structure of DNA and functioning of enzyme system, exhibiting neurotoxic properties. The signals coming to a single arm or leg muscle from upper and lower motor neurons are highly determinative in diagnosis of the disease, although there is not a specific test for diagnosing the ALS disease for certain. Doctors still conduct many tests even though the main symptoms of ALS are the signals coming to muscles. The developments related to gait analysis are used an auxiliary factor in diagnosis and analys is of ALS diseases. In this study, gait signals from control individuals and ALS diseases have been recorded by means of sensors sensitive to the strength under the foot. These signals' time-amplitude, amplitude spectrum, phase spectrum, average value and variance changes have been analysed. As a result of these inspections, differences of ALS signals from control signals have been identified.
\end{abstract}

Index Terms - ALS Disease, Gait Test, Spectral Analysis, Statistical Analysis.

\section{INTRODUCTION}

$\mathrm{W}$ ALKING IS ADVANCING the body for the purpose of being able to go from one place to another. Though walking seems to be a very simple part of the life, actually it is an extremely chain of complex movements. For being able to walk without tiring for a long time without getting tired; brain, spinal cord, peripheral nerves, muscles, bones and joints

OMER AKGUN, is with Department of Computer Engineering University of Marmara, Istanbul, Turkey,(e-mail: oakgun@ marmara.edu.tr).

iD https://orcid.org/ 0000-0003-3486-2197

A YDIN AKAN, is with Department of Biomedical Engineering University of Izmir Katip Celebi, (e-mail: aydin.akan ikcu.edu.tr).

iD https://orcid.org/0000-0001-8894-5794

OZGUR YILMAZ, is with Department of Computer Education \& Instructional Technology İstanbul University-Cerrahpaşa, Istanbul, Turkey, (e-mail: oyilmazistanbul.edu.tr).

(iD https://orcid.org/0000-0002-1122-4558

Manuscript received January 25, 2020; accepted March 18, 2020. DOI: $\underline{10.17694 / \text { bajece. } 679926}$ should work together, joint movement, time and strength of contraction should be sufficient [1,2].

The complexity of normal walking and the difficulty of assessment with naked eyes have compelled scientists to develop detailed and reliable examination methods. Scientific assessment of human motion dates back to the era of Aristotle. Aristotle has found in B.C. 350 that joist movements are done by muscle constraints, after a few centuries Galen (A.D. 131201) has suggested that muscle contraction is managed by nerves. During the Renaissance the x period Galile's student Borelli, and in the 19th century Marey have performed dynamic studies regarding the human gait $[3,4]$. Eadweard Muybridge, the famous photographer has contributed significantly to the gait analysis in the late nineteenth century. A next stage in development of gait analysis is the conversion of photo images into numerical variables by Braune and Fisher in 1895. In 1930s, Eberhart and Inman have repeated these experiments in more detail by using a perforated disk rotating in front of the lens of the camera. The researchers who have put scientific gait analysis into clinical use as we know it today by dint of their studies began in 1950s are Verne Inman and Jacquelin Perry [1,3]. Gait analysis systems intended for clinical use have been developed by virtue of rapid development of personal computers began in 1980s, and they have been put up for sale and come into use in many countries around the world.

In today's context, the gait analysis is the numerical evaluation, identification and interpretation of the walking. Although many gait problems can be detected through visual inspections of experienced physicians, the gait analysis technology is required in order to interpret the problem numerically, to re-evaluate after saving it and to demonstrate the effectiveness of the treatment done in an objective manner. The gait of the patient is firstly assessed by looking with eyes and video recordings in modern gait analysis laboratories. Afterwards the motion data is transferred to the computer by means of transmitter or reflectors attached to appropriate points on the patient's body, and also ground reaction strength variations which are measured while pressing on a force platform mounted on the ground is installed into computer. In addition to these data dynamic electromyography and energy consumption measurements are also made in advanced laboratories. All these information are converted into digital data via custom software. Finally, it is diagnosed by evaluating the data together with clinical condition of the patient $[3,4]$.

The studies within the scope of this article regarding the numerical assessment of neurodegenerative diseases and gait 
dynamics have been done by Hausdorff and et.al. in the years of 1997 and 2000. These researches were usually based on analyses associated with gait rhythm $[5,6]$.

Meanwhile this study is based on kinetic analysis of gait dynamics. Kinetic analysis is an examination of forces forming the movement (ground reaction forces, joist moments, joist strengths). The only data that can be measured in kinetic analysis is the ground reaction force vector (YTKV). YTKV is measured with plates sensitive to pressure which is measuring the total force applied to the ground by foot and called force plate. Transducers, which have been placed at both sides, front and rear and inside of the platform, measure the components of the load coming on the force plate surface at every three planes and transfer this data to computer [7,9].

\section{DATA COLLECTION SYSTEM}

60-seconds gait signals have been recorded by utilizing piezoelectric sensors sensitive to the force under the foot, by means of sensors sensitive to strength from 14 Normal and 13 ALS patients. The signals have been transferred to computer environment by converting into 18000 pcs series $\mathrm{x}(\mathrm{n})$ discrete signals (Fig. 1). [1].

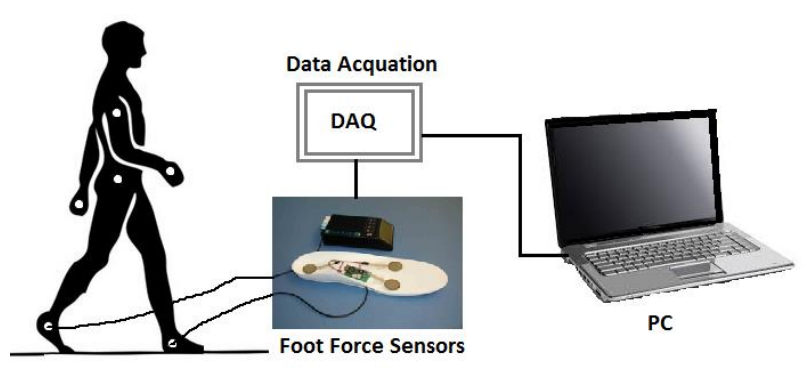

Fig.1. Data Collection System

\section{TIME-AMPLITUDE ANALYSIS}

The amplitude variations of the signal which will be analysed with time-amplitude analysis can be examined within time. It can be regarded as the most basic analysis. Variable electrical signals are a function of the time and frequency. Therefore, amplitude variations should be examined before making analyses of electrical signals on time and frequency plane. The change of these $\mathrm{x}(\mathrm{n})$ signs depending on time was shown in Fig.2.
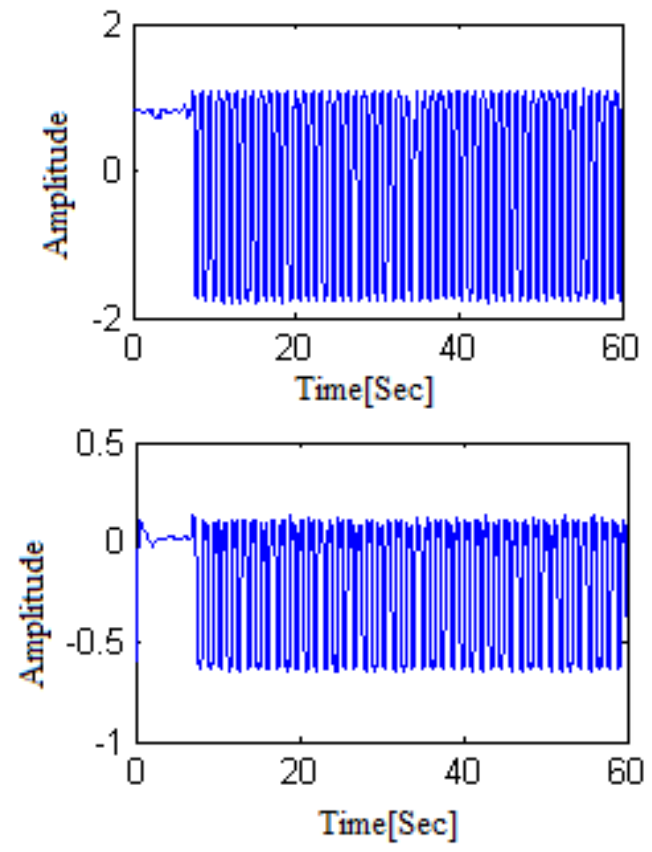

Fig.2. Control (upper) and ALS (lower) gait signals time-amplitude graphic

TABLE I

MAX. AND MIN. OF GAIT SIGNALS

\begin{tabular}{|c|c|c|c|c|}
\hline $\begin{array}{c}\text { Patient } \\
\text { No }\end{array}$ & \multicolumn{2}{|c|}{ Control } & \multicolumn{2}{c|}{ ALS } \\
\hline & Max & Min & Max & Min \\
\hline 1 & 0.3 & -0.6 & 0 & -0.6 \\
\hline 2 & 0.2 & -0.6 & 0.2 & -0.5 \\
\hline 3 & 0 & -0.6 & 0.1 & -0.6 \\
\hline 4 & 0 & -0.6 & 0 & -0.5 \\
\hline 5 & 0.7 & -2 & 0.1 & -0.6 \\
\hline 6 & 0.2 & -2 & -0.1 & -0.6 \\
\hline 7 & 0.1 & -0.6 & 0.1 & -0.6 \\
\hline 8 & 0.5 & -2 & 0 & -1.6 \\
\hline 9 & 1 & -1.7 & 0.2 & -0.6 \\
\hline 10 & 0.8 & -1.8 & 0 & -0.6 \\
\hline 11 & 0.4 & -2 & 0.1 & -0.6 \\
\hline 12 & 0.2 & -0.6 & 0 & -0.6 \\
\hline 13 & 0.5 & -2 & 0 & -0.6 \\
\hline 14 & 0.3 & -0.6 & & \\
\hline
\end{tabular}

ALS signals observed in Fig. 2 and Table 1 take the 0,0.1 and 0.2 values for max. and -0.6 and -0.5 values for min. It is seen that there are deviations in control signals.

\section{AMPLITUDE AND PHASE SPECTRUM ANALYSIS}

The analysis made on the frequency plane is called spectrum analysis. The energy levels are specified of the signals in respect of different frequencies forming any signal in spectrum analysis. Electrical and physical information, which are useful for the test of electrical and mechanic 
systems are obtained with this analysis.

The discrete Fourier transformation, which is defined with the expression of

$$
X[k]=\sum_{n=0}^{N-1} x(n) e^{-j(2 \pi / N) k n}, k=0,1, \ldots \ldots ., N-1
$$

was applied to $x(n)$ signs in order to find amplitude and phase spectrums of $x(n)$ gait signals.

The amplitude spectrums of control and ALS gait signals are seen in Fig.3 [10,12].
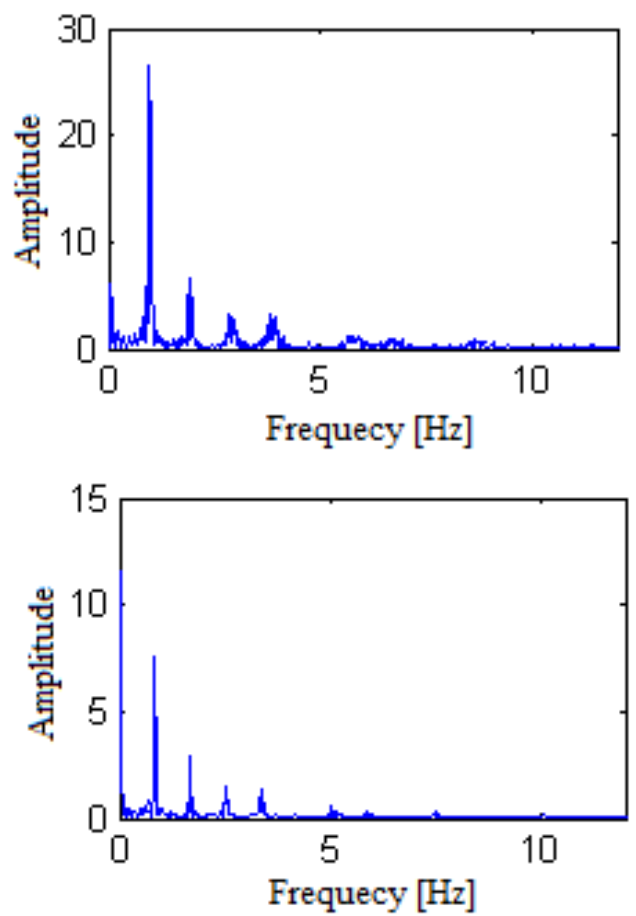

Fig.3. The amplitude spectrums of control (upper) and ALS (lower) signals

TABLE II

MAX. SPECTRAL AMPLITUDE VALUES

\begin{tabular}{|c|c|c|}
\hline PatientNo & Control & ALS \\
\hline 1 & 10.2 & 3.6 \\
\hline 2 & 12.4 & 8.3 \\
\hline 3 & 7.8 & 9.6 \\
\hline 4 & 6.1 & 4.2 \\
\hline 5 & 39.2 & 4.7 \\
\hline 6 & 21.5 & 4 \\
\hline 7 & 79 & 5.7 \\
\hline 8 & 26.3 & 8.7 \\
\hline 9 & 26.6 & 9.9 \\
\hline 10 & 30.2 & 8.6 \\
\hline 11 & 22.9 & 7.6 \\
\hline 12 & 8.7 & 9 \\
\hline 13 & 21.6 & 6.5 \\
\hline 14 & 73 & \\
\hline
\end{tabular}

When Figure 3 and Table 2 are scrutinized, it is noteworthy that spectral amplitude values of ALS signals around $1 \mathrm{~Hz}$ are smaller than those of control signals. Meanwhile in Figure 3, the phase spectrums of control and ALS gait signals have been given in Fig.3.
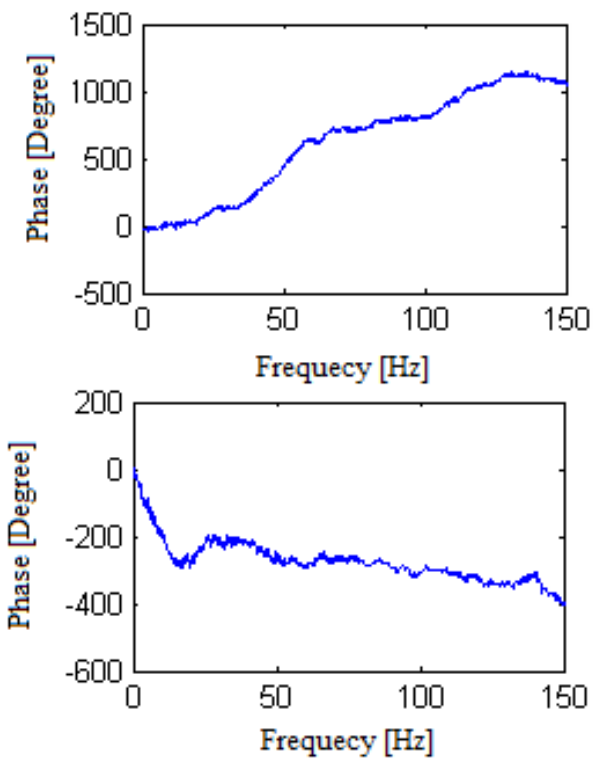

Fig.4. The phase spectra of control (upper) and ALS (lower) signals

It is seen that the inclinations are smaller in spectral graphics in Fig.4 and of ALS signals in Table 3.

TABLE III

THE MAX. AND MIN. DEGREE VALUES REACHED BY CURVES IN PHASE SPECTRA

\begin{tabular}{|c|c|c|c|c|}
\hline $\begin{array}{c}\text { Patient } \\
\text { No }\end{array}$ & \multicolumn{2}{|c|}{ Control } & \multicolumn{2}{c|}{ ALS } \\
\hline & Max & Min & Max & Min \\
\hline 1 & 1134 & -180 & 1339 & -48 \\
\hline 2 & 7 & -459 & 1600 & -235 \\
\hline 3 & 100 & -114 & 670 & -35 \\
\hline 4 & 534 & -35 & 829 & 0 \\
\hline 5 & 12 & -500 & 645 & -32 \\
\hline 6 & 311 & -46 & 802 & -41 \\
\hline 7 & 3049 & -20 & 350 & -28 \\
\hline 8 & 1221 & 0 & 395 & -84 \\
\hline 9 & 1072 & -31 & 261 & -91 \\
\hline 10 & 289 & -102 & 529 & -136 \\
\hline 11 & 1952 & -93 & 0 & -400 \\
\hline 12 & 1081 & -200 & 17 & -42 \\
\hline 13 & 455 & -154 & 204 & -89 \\
\hline 14 & 603 & -74 & & \\
\hline
\end{tabular}




\section{STATISTICAL ANALYSIS}

One of the special values that can be defined the distribution of $\mathrm{X}$ gait signals is the expected values of signals, and the other one is the variance. The expected values of $\mathrm{X}$ gait signals are defined by expression of

$$
E(X)=\sum_{n=1}^{18000} x_{n} P\left(X=x_{n}\right)
$$

Consider the average of $\mathrm{X}$ as. In this case, the variance of $\mathrm{X}$ is calculated as the total of [7-13].

$$
\sigma^{2}=E(X-\mu)^{2}=\sum_{n=1}^{18000}\left(x_{n}-\mu\right)^{2} P\left(X=x_{n}\right)
$$

\section{TABLE IV}

AVERAGE VALUES AND VARIANCES OF CONTROL AND ALS GAIT SIGNALS

\begin{tabular}{|c|c|c|c|c|}
\hline $\begin{array}{c}\text { Patient } \\
\text { No }\end{array}$ & $\begin{array}{c}\text { Control } \\
\text { Mean }\end{array}$ & $\begin{array}{c}\text { ALS } \\
\text { Mean }\end{array}$ & $\begin{array}{c}\text { Control } \\
\text { Variance }\end{array}$ & $\begin{array}{c}\text { ALS } \\
\text { Variance }\end{array}$ \\
\hline 1 & -0.062 & -0.323 & 0.121 & 0.038 \\
\hline 2 & -0.128 & -0.018 & 0.137 & 0.083 \\
\hline 3 & -0.308 & -0.234 & 0.069 & 0.088 \\
\hline 4 & -0.323 & -0.151 & 0.069 & 0.043 \\
\hline 5 & -0.461 & -0.234 & 1.240 & 0.055 \\
\hline 6 & -0.858 & -0.341 & 0.816 & 0.040 \\
\hline 7 & -0.259 & -0.197 & 0.080 & 0.081 \\
\hline 8 & -0.682 & -1.055 & 1.001 & 0.168 \\
\hline 9 & 0.00007 & -0.211 & 1.428 & 0.113 \\
\hline 10 & -0.267 & -0.281 & 1.385 & 0.064 \\
\hline 11 & -0.694 & -0.191 & 0.958 & 0.094 \\
\hline 12 & -0.117 & -0.268 & 0.129 & 0.072 \\
\hline 13 & -0.528 & -0.236 & 1.040 & 0.079 \\
\hline 14 & -0.089 & & 0.139 & \\
\hline
\end{tabular}

When the Table 4 is examined; the average values of ALS gait signals take values usually around -0.2. Meanwhile it has been observed in an inspection according to variance values that ALS signals were taking quite small values compared to control signals.

\section{CONCLUSION}

Today there are over 30000 people living with ALS disease. This disease causes progressive degeneration of motor neurons in the body affecting the voluntary muscle control. At the end, those affected loses their livelihood, independence and eventually their lives. Occurrence of upper and lower motor nerve cells symptoms together are characteristic. For individuals suffering this disease, the upper motor neuron symptoms are excessive reflexes, stiffness, rising upward of thumb and reflex increase at the chin, and the lower motor neuron symptoms are weakness, muscle weakness, cramps and twitches. The disease varies from person to person. In this study, gait dynamics test was done in determination of ALS disease. The findings obtained from test results are rather satisfactory. The results of analyses can be enumerated as below.

$\square$ ALS gait signals take certain max. values in timeamplitude analysis $(0,0.1,0.2)$.

$\square$ The amplitudes of ALS gait signals in the amplitude spectrum are notable with small values.

$\square$ The phase curves of ALS gait signals in the phase spectrum manifest themselves with small inclinations.

ALS signals are diagnosed with average values at around -0.2. Moreover their variances have been identified as a distinguishing feature specific to ALS signals with pretty small values.

\section{REFERENCES}

[1] O. Akgun, H. Demir, A. Akan, , "Detection of ALS Disease Using AR Models of Gait Dynamics", Electrical, Electronic and Computer Engineering Symposium (ELECO), 26-30 November 2008, Bursa Turkey.

[2] J. Perry , Gait Analysis: Normal and Pathological Function, Slack Incorporated Thorofare, NJ, 1992.

[3] S. Yalçın, N. Özaras , Gait Analysis, Avrupa Publications, Istanbul, 2001 (inTurkish).

[4] M. Whittle , Gait Analysis: an introduction, Butterworth Heinemann, Oxford, 1993.

[5] J.M. Hausdorff, S.L. Mitchell, R. Firtion, C.K. Peng, M.E. Cudkowicz, J.Y. Wei, A.L. Goldberger, "Altered fractal dynamics of gait: reduced stride-interval correlations with aging and Huntington's disease", J. Applied Physiology, Vol. 82, 1997, pp.262-269.

[6] J.M. Hausdorff, A. Lertratanakul, M.E. Cudkowicz, A.L. Peterson, D. Kaliton, A.L. Goldberger, "Dynamic markers of altered gait rhythm in amyotrophic lateral sclerosis" J. Applied Physiology, Vol. 88, 2000, pp.2045-2053.

[7] J.R. Gage, "The clinical use of kinetics for the evaluation of pathological gait in ce-rebral palsy", Instr Course Lect., Vol 44, 1995, pp.507-15.

[8] F. Akdeniz, Probability and Statistics, Nobel Medical Publications, Istanbul, 2004.

[9] T. Liu, Y. Inoue, K. Shibata, K. Shiojima, "Three-dimensional gait analysis system with mobile force plates and motion sensors", Ubiquitous Robots and Ambient Intelligence (URAI), 2011 8th International Conference on 2011, pp. 107-110.

[10] S. Tallapragada, L.V.C. Srinivas, "Marker less view independent gait analysis using DFT", Electronics Computer Technology (ICECT), 2011 3rd International Conference on Vol. 3, 2011, pp. 11-13.

[11] J.H. Yoo, M.S. Nixon, C.J. Harris, "Model-driven statistical analysis of human gait motion", Image Processing. 2002. Proceedings. 2002 International Conference on Vol. 1, 2002, pp.285-288.

[12] E. Onal, J. Dikun, "Short-Time Fourier Transform for Different Impulse Measurements". Balkan Journal of Electrical \& Computer Engineering, Vol.1, No.1, 2013, p.44-47.

[13] Y. Wu, S. Krishnan, "Statistical Analysis of Gait Rhythm in Patients With Parkinson's Disease", Neural Systems and Rehabilitation Engineering, IEEE Transactions on Vol. 18. 2, 2010 , pp. 150-158. 


\section{BIOGRAPHIES}

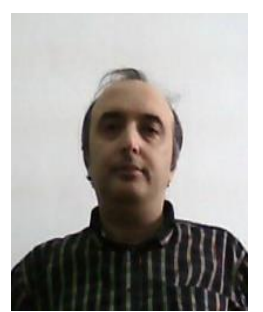

OMER AKGUN is an assistant professor at the, Department of Computer Engineering, Technology Faculty, Marmara University. $\mathrm{He}$ received his first $\mathrm{Ph} . \mathrm{D}$. in the Communication Engineering in 2009 from Yildiz Technical University and the second Ph.D. in the Electronic and Communication Education Department in 2011 from Marmara University. His current research interests are signal processing, biomedical signal processing, signal modelling and communication systems.

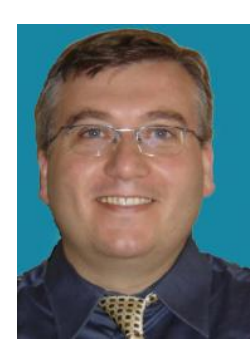

AYDIN AKAN received his Ph.D. degree in Electrical Engineering from the University of Pittsburgh, Pittsburgh, PA, USA, in 1996. He has been with the Department of Electrical and Electronics Engineering, Istanbul University, between 1996 and 2017. Currently he holds a Professor position at the department of Biomedical Engineering, Izmir Katip Celebi University, since 2017. His research interests are non-stationary signal processing, time-frequency signal analysis methods and their applications to wireless communications and biomedical engineering. Dr. Akan is a senior member of the IEEE Signal Processing Society and editorial board member of the Digital Signal Processing Journal.

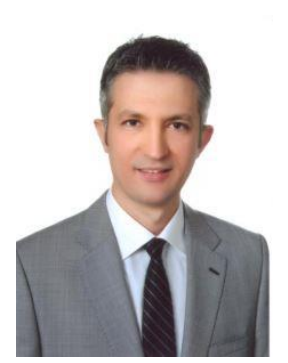

OZGUR YILMAZ, graduated with a bachelor's degree in 2000 from Department of Electrical Education, Marmara University, Turkey. He received M.S. and $\mathrm{PhD}$. degrees in Electrical Education from the Institute for Graduate Studies in Pure and Applied Sciences, Marmara University, in 2003 and 2010, with his dissertation titled "Web Supported Design, Teaching, and Evaluation of the Electromechanical Systems Course." He has worked as an Assistant Professor at İstanbul University-Cerrahpaşa. He has published numerous papers on mechatronics education, distance education and game-based learning. His current research focuses on game-based learning and distance education 